\title{
Effect of mineral additives on structure and properties of concrete for pavements
}

\author{
Khrystyna Sobol, Taras Markiv, Oleksii Hunyak \\ Lviv Polytechnic National University \\ Institute of Building and Environmental Engineering \\ e-mail:khrystynasobol@ukr.net, tmarkiv2@ukr.net,oleksii.m.guniak@lpnu.ua
}

\begin{abstract}
Concrete pavements is an attractive alternative to asphalt pavements because of its lower cost and higher durability. Major contribution to sustainable development can be made by partial replacement of cement in concrete pavement with supplementary cementitious materials of different nature and origin. In this paper, the effect of natural zeolite and perlite additives in complex with chemical admixtures on the structure and properties of concrete for pavement was studied. Compressive and flexural strength test was used to study the mechanical behavior of designed concrete under load. Generally, the compressive strength of both control concrete and concrete containing mineral additives levels at the later ages of hardening. The microstructure analysis of concrete with mineral additives of different nature activity showed the formation of additional amount of hydration products such as tobermorite type calcium hydrosilicate which provide self-reinforcement of hardening concrete system.
\end{abstract}

Key words: pavement concrete, slag, zeolite, perlite, compressive strength, structure

\section{Introduction}

Portland cement concrete pavements have been used worldwide as an alternative to asphalt pavements because of its durability, strength, service life, local availability of raw material, and lower cost. However, manufacturing of cement, a key ingredient used for the production of concrete, is an energy-intensive process which is also a major source of atmosphere pollution [1].

New trends in sustainable development of concrete infrastructure and in environmental regulations are inducing replacement of cement in pavement concrete [2, 3]. It can be done using mineral additives of natural or artificial origin. The addition of these additives, also called supplementary cementitious materials (SCMs) allows not only to reduce the environmental harm, but also to lower cost of concrete and to improve some of its properties [4].

Granulated blast furnace slag (GBFS) has been used for many years as a supplementary cementitious material in Portland cement concrete. It is the most widespread cement additive 
in Ukraine [5]. GBFS is non-metallic by-product of pig iron production consisting mainly of silicates and aluminosilicates of calcium that defines its latent hydraulic properties. GBFS usage as a cementitious component requires only grinding This can save considerable amounts of energy comparing with the manufacturing of ordinary Portland cement. Research results [6] show that partial replacement of clinker in cement and cement in concrete with GBFS may increase strength and considerably improve microstructure and durability of Portland cement and concrete.

Some materials, such as natural zeolite and perlite can be successfully used as supplementary cementitious materials or pozzolan in cement concrete pavement.

Natural zeolites are a group of hydrated alumosilicates, with a specific hierarchical structure. Clinoptilolite type of natural zeolite is well known for its good pozzolanic activity as well as its positive effect on durability of concrete [7].

Perlite, a hydrated alumosilicate volcanic glass with relatively high water content (between $2 \%$ and $5 \%$ ) characterizes by concentric onion-skin fractures. When rapidly heated it expands up to 20 times and transforms into expanded perlite, a cellular material with low bulk density. Natural perlite powder has a significant pozzolanic effect and is a good active mineral additive for concrete [8].

To obtain desired strength and durability of cement concrete pavement, maintenance of low water to cementious material ratio is essential along with the use of a superplasticiser and airentraining agent. The previous research [9] of concretes have shown, that combination of natural zeolite with chemical admixtures of plasticizing and air-entraining action result in the improvement of concrete properties and durability.

The goal of this research is to study the influence of natural zeolite and perlite additives in complex with chemical admixtures on the structure and properties of concrete for pavement.

\section{Materials and experimental methods}

\subsection{Materials}

The Portland-slag cement CEM II/A-S 42.5 was used in this study, which conforms to the current specifications as described in EN 196 [10]. Specific surface of cement was $350 \mathrm{~m}^{2} / \mathrm{kg}$, residue on sieve 008 was $3.1 \%$, initial and final setting time were 180 and $300 \mathrm{~min}$ respectively. Its chemical composition is given in Table 1 .

Table 1: Chemical compositions of cementitious materials

\begin{tabular}{|c|c|c|c|c|}
\hline \multicolumn{2}{|c|}{ Material } & CEM II/A-S 42,5 & Natural zeolite & Perlite \\
\hline \multirow{9}{*}{ 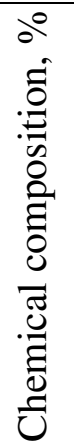 } & $\mathrm{SiO}_{2}$ & 23.20 & 75.34 & 71.78 \\
\hline & $\mathrm{Al}_{2} \mathrm{O}_{3}$ & 5.27 & 8.77 & 12.77 \\
\hline & $\mathrm{Fe}_{2} \mathrm{O}_{3}$ & 3.50 & 1.30 & 1.54 \\
\hline & $\mathrm{CaO}$ & 62.34 & 4,60 & 1.31 \\
\hline & $\mathrm{MgO}$ & 1.39 & 0.55 & 0.60 \\
\hline & $\mathrm{Na}_{2} \mathrm{O}$ & 0.11 & 1.22 & 3.00 \\
\hline & $\mathrm{K}_{2} \mathrm{O}$ & 0.96 & 5.41 & 4.10 \\
\hline & $\mathrm{SO}_{3}$ & 2.28 & 0.05 & 0.90 \\
\hline & LOI & 0.95 & 5.76 & 4.00 \\
\hline
\end{tabular}


The following materials were used as SCMs: clinoptilolite type natural zeolite from Sokyrnytsya deposite (Zakarpattya region, Ukraine) with bulk density of $876 \mathrm{~kg} / \mathrm{m}^{3}$ and fineness modulus of 1.47 , commercially available expanded perlite sand with bulk density of $67 \mathrm{~kg} / \mathrm{m}^{3}$ and fineness modulus of 1.52. Chemical compositions of SCM's are presented in Table 1 .

Crushed granite as coarse aggregate (maximum size of $20 \mathrm{~mm}$ ) was used. The bulk density of coarse aggregate was $1420 \mathrm{~kg} / \mathrm{m}^{3}$, voidage was $45 \%$. River sand was used as fine aggregate. The bulk density and the fineness modulus of sand were $1440 \mathrm{~kg} / \mathrm{m}^{3}$ and 1.8 respectively.

Commercially available polycarboxylate-based superplasticizer with a specific gravity of 1.05 and solid content of $20 \%$ and an air-entraining agent, based on vinsol resin, with specific gravity of 1.05 and solid content of $4.4 \%$, were used to improve properties and durability of concrete for pavements.

\subsection{Mix proportions}

In the first part of the study, 10 different types of fine-grained concrete (FGC) mixes with 1:3 binder to aggregate ratio were prepared. Two control FGC mixes without natural zeolite and perlite at water-to-cement ratio 0.39 and 0.5 and eight mixes made by replacing $5 \%$ and $10 \%$ of cement weight with natural zeolite and perlite at water-to-cement ratio 0.39 and 0.5 were prepared.

In the second part of study five concrete mixes with coarse aggregate (maximum size of 20 $\mathrm{mm}$ ) were designed. Their mix proportions are given in Table 2. The consistency class of concrete mixes was $\mathrm{S} 1$. Water-to-cement ratio for all concrete mixes ranged between 0.38 and 0.45 due to water reducing or increasing effect of both mineral additives and chemical admixtures.

Table 2: Concrete mix proportions and volume of entrained air

\begin{tabular}{|c|c|c|c|c|c|c|c|c|}
\hline \multirow{2}{*}{ 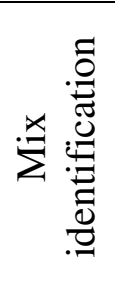 } & \multicolumn{3}{|c|}{$\begin{array}{l}\text { Amount of components in } \\
\text { concrete }\left(\mathrm{kg} / \mathrm{m}^{3}\right)\end{array}$} & \multicolumn{4}{|c|}{ Additives, wt. $\%$ of cement } & \multirow{2}{*}{ 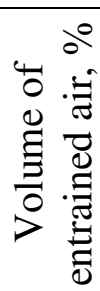 } \\
\hline & Cement & Sand & $\begin{array}{l}\text { Crushed } \\
\text { granite }\end{array}$ & Zeolite & Perlite & $\begin{array}{l}\text { Superpla- } \\
\text { sticizer }\end{array}$ & $\begin{array}{c}\text { Air } \\
\text { entraining } \\
\text { agent }\end{array}$ & \\
\hline PSC & 400 & 500 & 1250 & - & - & 1.0 & - & 1.8 \\
\hline $\mathrm{NZ}$ & 360 & 500 & 1250 & 10 & - & 1.0 & - & 2.3 \\
\hline$P$ & 360 & 500 & 1250 & - & 10 & 1.0 & - & 1.1 \\
\hline NZA & 360 & 500 & 1250 & 10 & - & 1.0 & 0,5 & 4.2 \\
\hline PA & 360 & 500 & 1250 & - & 10 & 1.0 & 0,5 & 4.0 \\
\hline
\end{tabular}

\subsection{Test methods and sample preparation}

FGC mix preparation was conducted according to EN 196-1 procedure [10]. Prepared finegrained concretes with mineral additives were cast in 40x40x160 mm prismatic moulds. The specimens were removed from the moulds after 1 day and cured in water at $20 \pm 1{ }^{\circ} \mathrm{C}$. The strength tests of the specimens were conducted on days 2, 7 and 28. 
Laboratory pan mixer with 30-liter capacity was used for the preparation of concrete mixes. Concrete cube specimens of 100x100x100 mm were prepared to determine compressive strength; beams of 100x100x400 mm size were cast for flexural strength test. Moulds were filled with concrete mix in one layer and compacted by means of laboratory vibrating table. Volume of entrained air in concrete mix was measured using Testing 2.0334 device.

Microstructure of concrete was examined by scanning electron microscope SEM FEI Quanta 250 FEG, equipped with EDS.

\section{Result and discussion}

Compressive strength test was used to study the mechanical behavior of different fine-grained concretes under the load. The results for mixes with water-to-cement ratio 0.5 are given in Figure 1. According to the obtained results, there is no significant difference between compressive strength of zeolite and perlite incorporating FGC at early age of hardening. However, the fine-grained concrete containing $5 \mathrm{wt} . \%$ of perlite characterizes with somewhat higher compressive strength at 28 days of hardening than the control fine-grained concrete.
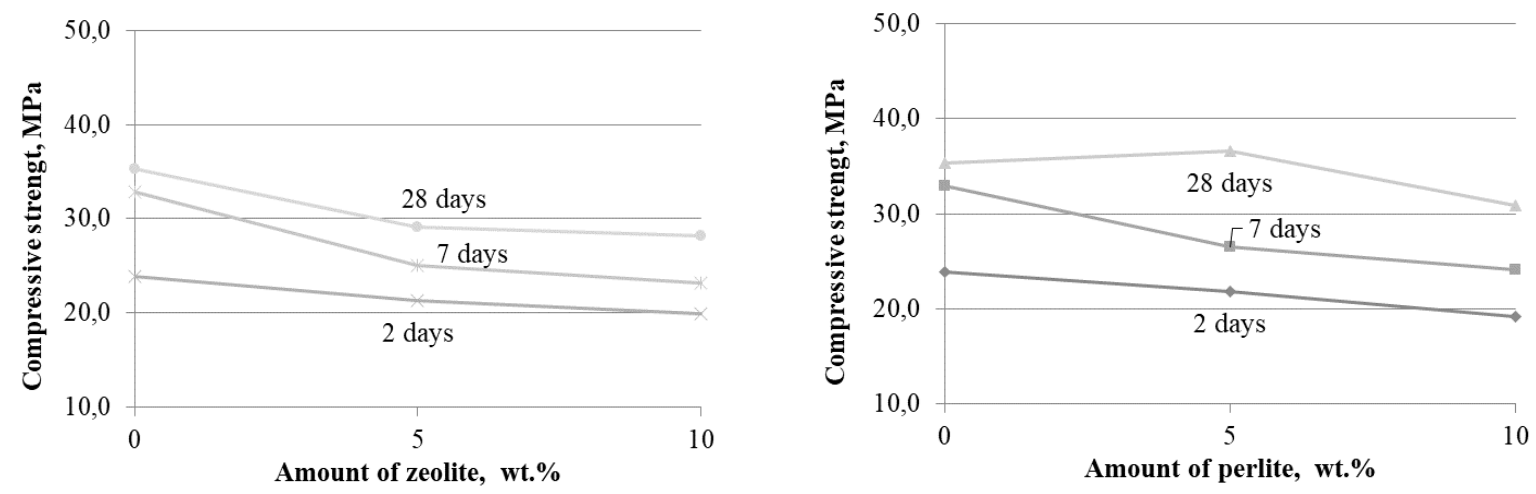

Figure 1: Compressive strength change of fine-grained concrete $(\mathrm{w} / \mathrm{c}=0.5)$

As seen from Figure 2, fine-grained concrete with water-to-cement ratio 0.39 were found to have generally higher compressive strength than that with w/c ratio 0.5. At the age of 2 days, the compressive strength of fine-grained concrete with $5 \mathrm{wt} \%$ perlite content were higher than that of the $5 \mathrm{wt} \%$ of zeolite, but at the age of 28 days of hardening the compressive strength of fine-grained concrete with zeolite is higher in comparison with the other ones.

The results of research of designed concretes with maximum size of $20 \mathrm{~mm}$ of coarse aggregate revealed that flexural strength of concretes containing natural zeolite and perlite is slightly higher than control concrete, in spite the lower content of Portland cement as can be seen in Table 3. Addition of air-entraining agent results in reducing naturally the flexural and compressive strength.

Compressive strength of concretes (20 mm maximum size of coarse aggregate) incorporating mineral additives and superplasticizer showed similar behavior as fine-grained concretes. 

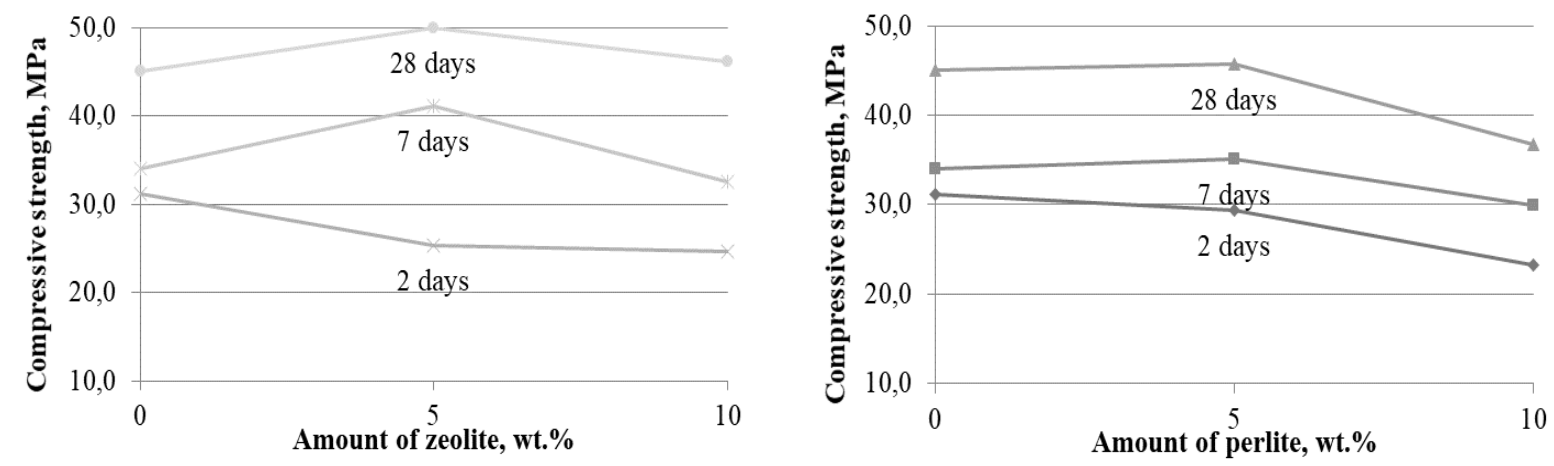

Figure 2: Compressive strength change of fine-grained concrete $(\mathrm{w} / \mathrm{c}=0.39)$

The obtained results show, that compressive strength of both control concrete and concrete containing mineral additives (without air entraining agent) levels at the age of 28 days of hardening. Yet concretes with air entraining agent NZA and PA showed naturally 13 and 12\% respectively lower value of compressive strength in comparison with concretes NZ and P.

Table 3: Compressive and flexural strength of concrete

\begin{tabular}{|c|c|c|c|c|}
\hline Mix identi- & Flexural strength & \multicolumn{3}{|c|}{ Compressive strength, MPa } \\
\cline { 3 - 5 } fication & at 28 days, MPa & 2 days & 7 days & 28 days \\
\hline PSC & 10.8 & 38.8 & 53.9 & 68.5 \\
\hline NZ & 11.2 & 38.7 & 55.2 & 69.2 \\
\hline P & 11.0 & 50.4 & 58.1 & 67.7 \\
\hline NZA & 10.4 & 33.2 & 48.9 & 60.4 \\
\hline PA & 10.4 & 45.1 & 51.6 & 59.4 \\
\hline
\end{tabular}

The switchover from systems where mineral mono-additives (i.e. slag, zeolite and perlite) were used to system containing composite binders leads to changes in the structure formation processes of concretes incorporating both hydraulic and pozzolanic additives.

Analysis of concrete microstructure shown in Figure 3 indicates the increase of entangled fibrous crystals of calcium silicate hydrate.
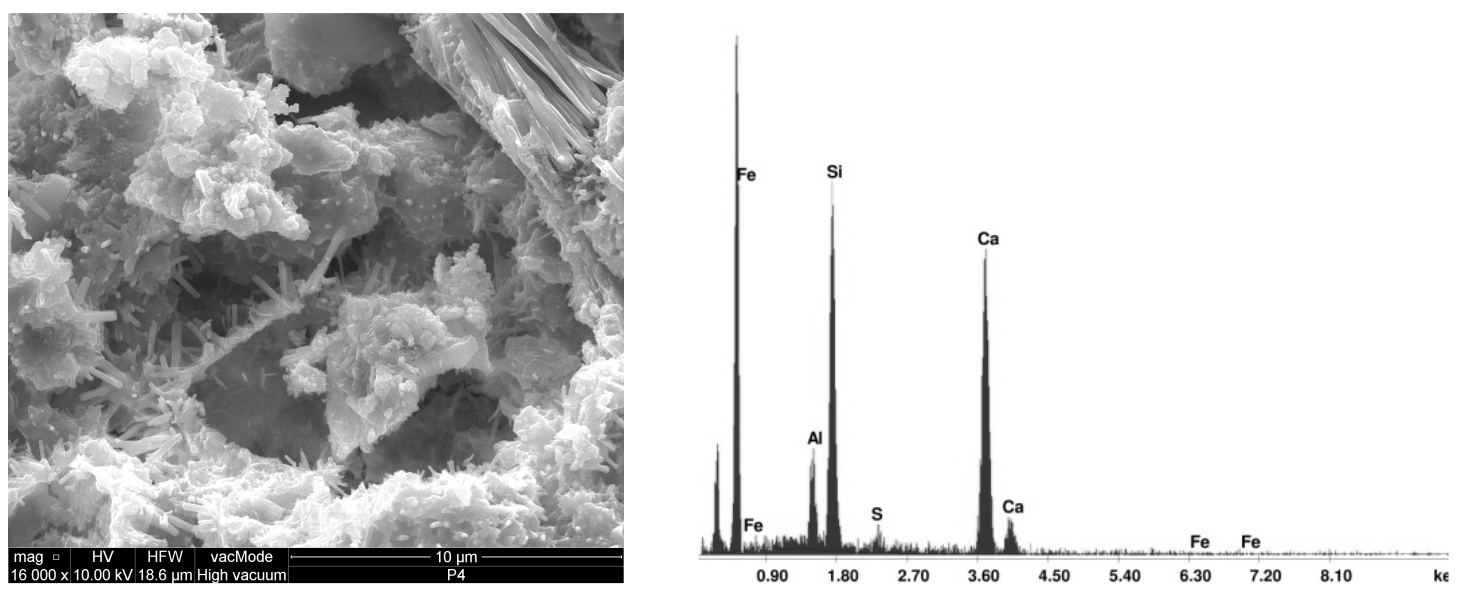

Figure 3: SEM image and EDX point analysis of concrete NZ after 28 days of hardening 
The microstructure of such concrete is more complex in comparison with concrete without additives, because mineral additives of different nature activity take part in reactions. This results in formation of additional amount of hydration products providing self-reinforcement of hardening concrete system.

\section{Conclusion}

Thus, the addition of mineral additives of pozzolanic nature activity namely perlite and zeolite into the system which contains granulated blast furnace slag effects the properties of cement concretes for pavement and changes their structure formation improving the compressive strength and durability.

\section{References}

[1] Worrell, E., Price, L., Martin, N., Hendriks, C., \& Meida, L. O. Carbon dioxide emissions from the global cement industry. Annual review of energy and the environment, vol. 26, 2001, no 1, p. 303-329.

[2] Mehta P.K. Greening of the concrete industry for sustainable development. Concrete international, vol. 24, 2002, no 7, p. 23-28.

[3] Ondova, M., Stevulova, N., \& Zelenakova, E. Energy savings and environmental benefits of fly ash utilization as partial cement replacement in the process of pavement building. Chemical Engineering Transactions, vol. 25, 2011, p. 297-302.

[4] Targan S., Olgun A., Erdogan Y., Sevinc V. Effects of supplementary cementing materials on the properties of cement and concrete, Cement Concrete Research, vol. 32, 2002, no 10, p. 15511558.

[5] Sanytskyy M.A., Sobol Kh.S., Markiv T.V. [Modified composite cements]. Lviv Polytechnic National University Publishing House, Lviv, 2010. [In Ukrainian].

[6] Shi, C., \& Qian, J. High performance cementing materials from industrial slags-a review. Resources, Conservation and Recycling, vol.29, 2000, no 3, p. 195-207.

[7] Ahmadi, B., Shekarchi, M. Use of natural zeolite as a supplementary cementitious material. Cement and Concrete Composites, vol. 32, 2010, no 2, p. 134-141.

[8] $\mathrm{Yu}, \mathrm{L} . \mathrm{H} ., \mathrm{Ou}, \mathrm{H}$. , \& Lee, L. L. Investigation on pozzolanic effect of perlite powder in concrete. Cement and Concrete Research, vol. 33, 2003, no 1, p. 73-76.

[9] Markiv, T., Sobol, K., Franus, M., \& Franus, W. Mechanical and durability properties of concretes incorporating natural zeolite. Archives of Civil and Mechanical Engineering, vol. 16, 2016, no 4, p. 554-562.

[10] BS EN 196, Method of testing cement. British Standards Institution, London, 2016. 